\title{
Effects of La on Microstructure and Corrosion Behavior of AlSi5Cu1Mg Alloy
}

\author{
Bao-Biao $\mathrm{Yu}^{1,2} \cdot$ Hong $\mathrm{Yan}^{1,2} \cdot$ Jian-Bin $\mathrm{Zhu}^{1,2} \cdot$ Jian-Long $\mathrm{Liu}^{3} \cdot$ Huo-Gen $\mathrm{Li}^{3} \cdot$ Qiao $\mathrm{Nie}^{3}$
}

Received: 17 April 2018/Revised: 15 May 2018/Published online: 12 July 2018

(C) The Chinese Society for Metals and Springer-Verlag GmbH Germany, part of Springer Nature 2018

\begin{abstract}
The microstructures and corrosion behavior of AlSi5Cu1Mg alloy modified with different contents of La were investigated. Optical microscopy observations showed that the microstructures of AlSi5Cu1Mg- $-\mathrm{La}(x=0,0.3,0.6$, and $0.9 \mathrm{wt} \%)$ alloy transformed from coarse cellular to fine cellular as the content of La increased from 0 to $0.9 \mathrm{wt} \%$. The results of electrochemical measurement and immersion test in $3.5 \mathrm{wt} \% \mathrm{NaCl}$ solution showed that the corrosion resistance of AlSi5Cu1Mg $-x \mathrm{La}$ alloy strongly depended on its microstructures. The AlSi5Cu1Mg- $0.6 \mathrm{La}$ sample exhibited the highest corrosion resistance due to its fine cellular structure and the cathode phases coated by the La element. The covering film of La hindered the corrosion electron flowing between the cathode and the anode. As a result, the corrosion current density of the AlSi5Cu1Mg-0.6La alloy was only about $40 \%$ that of the matrix alloy in the electrochemical measurement.
\end{abstract}

Keywords $\mathrm{La} \cdot \mathrm{AlSi} 5 \mathrm{Cu} 1 \mathrm{Mg}$ alloy $\cdot$ Microstructure $\cdot$ Corrosion behavior

\section{Introduction}

Al-Si alloys have been widely used as casting alloys due to their excellent casting properties. Especially in the automotive industry, where lightweight and high stress materials are advocated, many parts have been fabricated by $\mathrm{Al}-\mathrm{Si}$ alloys such as the wheel hub [1] and the cylinder cover [2]. However, it is well known that the needle-like eutectic $\mathrm{Si}$ in the unmodified Al-Si alloys would deteriorate its casting properties and mechanical properties [3-5]. Except needle-like eutectic $\mathrm{Si}, \mathrm{Al}-\mathrm{Si}$ alloys also usually contain $\mathrm{Al}_{2} \mathrm{Cu}$ and $\mathrm{Al}-\mathrm{Fe}-\mathrm{Si}$ intermetallic compounds. These inclusions contain more noble elements than the $\alpha$ $\mathrm{Al}$ matrix in seawater and could cause the alloys to be

Available online at http://link.springer.com/journal/40195

Hong Yan

hyan@ncu.edu.cn

1 School of Mechanical and Electrical Engineering, Nanchang University, Nanchang 330031, China

2 Key Laboratory of Light Alloy Preparation and Processing in Nanchang City, Nanchang 330031, China

3 Jiangxi Ling-Ge Non-ferrous Metal Processing Co., Ltd., Nanchang 330008, China locally corroded in the seawater [6-8], limiting the application of the alloys to terrestrial environments.

Several approaches have been developed to improve the corrosion resistance of the aluminum alloys by rare earth. The aluminum alloy was immersed in a solution containing rare earth elements to form a corrosion resistance coating on the surface of aluminum alloy $[9,10]$. A corrosion resistance layer containing rare earth elements was deposited on the surface of aluminum alloy by laser $[11,12]$. The rare earth master alloy was added in the molten aluminum alloy to improve the corrosion resistance of the base alloy $[13,14]$. The immersion coating and the laser clad coating methods with rare earth elements are a surface treatment method. If the surface coating is worn or consumed, the continued protection of the matrix material would be compromised. Therefore, these methods cannot essentially change the corrosion resistance of aluminum alloy. However, the method of rare earth modification not only improves the corrosion resistance of the aluminum alloy but also improves the mechanical properties and fluidity of aluminum alloy. For example, Cardinale et al. [15] showed that the addition of individual rare earth (La, $\mathrm{Pr}, \mathrm{Nd}, \mathrm{Sm}, \mathrm{Gd}, \mathrm{Tb}$, Dy or Er) can increase the corrosion resistance of the as cast $\mathrm{Al}-\mathrm{Si}$ alloy in $3.5 \mathrm{wt} \% \mathrm{NaCl}$ solution. Mao et al. [16] reported that the tensile strength and elongation of the $\mathrm{Al}-\mathrm{Si}$ alloy with $\mathrm{Eu}$ addition 
increased by 15.9 and $14.7 \%$, respectively, compared to the matrix alloy due to the modification effect of $\mathrm{Eu}$ on the morphology of $\mathrm{Si}$ and $\mathrm{Al}$ grain. Li et al. [17] reported that the fluidity length of Al-Si alloy with $0.6 \mathrm{wt} \% \mathrm{La}$ was $1321 \mathrm{~mm}$ and improved $38.91 \%$ compared to the one of the base alloys. This mainly benefited from the range of crystallization temperature decreases due to the addition of La.

Although Al-Si alloys modified with rare earth have been investigated, there is still a lack of detailed investigation on the corrosion resistance of AlSi5Cu1Mg alloy modified via La. In particular, the effect of a La-rich phase on corrosion properties of the AlSi5Cu1Mg alloy has not been clarified. Hence, it is meaningful to determinate the corrosion resistance mechanism of the $\mathrm{AlSi} 5 \mathrm{Cu} 1 \mathrm{Mg}$ alloy with La additives. The aim of the present study was to investigate the effect of La addition on the microstructures and corrosion resistance of the raw AlSi5Cu1Mg alloy. The main attention was focused on the effect of the La-rich phase on the corrosion properties of the $\mathrm{AlSi} 5 \mathrm{Cu} 1 \mathrm{Mg}$ alloy.

\section{Experimental}

The AlSi5Cu1Mg alloy was used as matrix in this investigation. The AlSi5Cu1Mg alloy was molten in a graphite crucible at a pouring temperature of $720{ }^{\circ} \mathrm{C}$ by an electric resistance furnace (Zhuochi SK3-3-10-4; Hangzhou, China) under the shelter of $\mathrm{CO}_{2}$ and $\mathrm{SF}_{6}$ gases. The chemical compositions of AlSi5Cu1Mg- $x \mathrm{La}(x=0,0.3$, 0.6 , and $0.9 \mathrm{wt} \%$ ) alloy were analyzed via ICP-AES (inductively coupled plasma atomic emission spectroscopy), and the results are shown in Table 1. After the AlSi5$\mathrm{Cu} 1 \mathrm{Mg}$ alloy was completely molten, the Al-10La master alloy was put into the molten alloy and mechanical agitation was applied to fabricate $\mathrm{AlSi} 5 \mathrm{Cu} 1 \mathrm{Mg}$ alloy with $\mathrm{La}$ additive. The molten alloy was isothermally held at $720{ }^{\circ} \mathrm{C}$ and intensively stirred for $30 \mathrm{~min}$ to ensure the complete dissolution of the La elements and other alloy elements. Then, the molten alloy was finally poured into a steel mold.

Samples of the AlSi5Cu1Mg- $x$ La columnar cast ingot bars were longitudinally cut, ground by sandpaper from 100 to 2000 , and then etched by $0.5 \mathrm{wt} \%$ hydrofluoric acid solution. The microstructures of the specimens were observed via optical microscopy (Nican M200, Nican, Tokyo, Japan).

For microstructure characterization, the sample was transversely cut beneath the columnar roots. The samples were ground and polished, but not etched. Phases in the AlSi5Cu1Mg- $x$ La alloy were characterized via scanning electron microscopy (SEM) (FEI Quanta 200F, FEI Company, Hillsboro, Oregon) equipped with energy-dispersive spectroscopy (EDS) (JSM-6701F, JEOL Ltd., Tokyo, Japan). The SEM was operated at $30 \mathrm{kV}$.

Samples for electrochemical measurements were $10 \mathrm{~mm} \times 10 \mathrm{~mm} \times 3 \mathrm{~mm}$ rectangles that were longitudinally cut from the columnar cast ingot bars. Before the electrochemical tests, the samples were encapsulated in epoxy resin leaving a $10 \mathrm{~mm} \times 10 \mathrm{~mm}$ surface, ground to 2000 grit via SiC emery paper, ultrasonically cleaned in acetone and then dried in cold air. The electrochemical tests were performed by a princeton applied research (PARSTAT 4000) and a three-electrode test system. The counter and reference electrodes were platinum electrode and silver/silver chloride $(\mathrm{Ag} / \mathrm{AgCl}$ in $3 \mathrm{~mol} / \mathrm{L} \mathrm{KCl})$, respectively. Linear scan voltammetry (LSV) test in naturally aerated $3.5 \mathrm{wt} \% \mathrm{NaCl}$ solution $\left(20^{\circ} \mathrm{C}, \mathrm{pH} 6.5\right)$ at a scanning rate of $1 \mathrm{mV} / \mathrm{s}$ starting from -300 to $300 \mathrm{mV}$ was conducted. The open circuit potential monitored before linear scan voltammetry and the scanning voltage was chosen with respect to the open circuit potential. The linear scan voltammetry curve was analyzed by matching analysis software (VersaStudio software, $\mathrm{P} / \mathrm{N}$ 224181). All electrochemical test results are presented as the mean values of six measurements.

For the immersion test, the AlSi5Cu1Mg- $x$ La samples ( $\Phi 10 \mathrm{~mm} \times 10 \mathrm{~mm}$ cylindrical specimens) were immersed in $3.5 \mathrm{wt} \% \mathrm{NaCl}$ solution (solution temperature was $25 \pm 2{ }^{\circ} \mathrm{C}$ ) for 60 days. The ratio of sample surface area $\left(\mathrm{cm}^{2}\right)$ to the volume of $\mathrm{NaCl}$ solution $(\mathrm{mL})$ was set to 1:100. Prior to immersion, the specimens were successively polished to 1000 grit via SiC emery paper followed by cleaning via ultrasonic cleaner (Deyisheng CJ008; Shengzhen; China) with ethanol solution (95 wt\%) for $5 \mathrm{~min}$.
Table 1 Chemical compositions of $\mathrm{AlSi} 5 \mathrm{Cu} 1 \mathrm{Mg}-x \mathrm{La}$ alloy (wt\%)

\begin{tabular}{lllllllll}
\hline Alloy & $\mathrm{Si}$ & $\mathrm{Cu}$ & $\mathrm{Mg}$ & $\mathrm{Fe}$ & $\mathrm{Zn}$ & $\mathrm{Mn}$ & $\mathrm{La}$ & $\mathrm{Al}$ \\
\hline AlSi5Cu1Mg & 5.40 & 1.05 & 0.43 & 0.59 & 0.14 & 0.32 & - & Bal. \\
AlSi5Cu1Mg-0.3La & 5.20 & 1.03 & 0.41 & 0.60 & 0.11 & 0.28 & 0.30 & Bal. \\
AlSi5Cu1Mg-0.6La & 5.20 & 0.99 & 0.45 & 0.61 & 0.17 & 0.31 & 0.61 & Bal. \\
AlSi5Cu1Mg-0.9La & 5.20 & 1.03 & 0.40 & 0.61 & 0.14 & 0.27 & 0.87 & Bal. \\
\hline
\end{tabular}




\section{Results and Discussion}

\subsection{Microstructure of AlSi5Cu1Mg Alloy with La Addition}

The microstructures of AlSi5Cu1Mg- $x \mathrm{La}$ aluminum alloys are shown in Fig. 1. As shown in Fig. 1a, the AlSi5Cu1Mg alloy without La addition contains coarse $\alpha$-Al dendrites, long-needle-like silicon phase and a fish-bone-like AlFeMnSi-type phase. As shown in Fig. 1b, the $\alpha$-Al, eutectic silicon and AlFeMnSi-type phase in the AlSi5$\mathrm{Cu} 1 \mathrm{Mg}-0.3 \mathrm{La}$ alloy are finer and more uniformly distributed than those of $\mathrm{AlSi} 5 \mathrm{Cu} 1 \mathrm{Mg}$ alloy without $\mathrm{La}$ addition shown in Fig. 1a; furthermore, the fish-bone-like AlFeMnSi-type phase was smaller compared to that in the AlSi5Cu1Mg-0.3La alloy. As shown in Fig. 1c, when the added $\mathrm{La}$ content reached $0.6 \mathrm{wt} \%$, the $\alpha$-Al exhibited nearly spherical shape, Si and AlFeMnSi-type phases were divided into granular or short rod-like and were well distributed in the matrix. However, when the La content increased to $0.9 \mathrm{wt} \%, \alpha-\mathrm{Al}, \mathrm{Si}$ and $\mathrm{AlFeMnSi-type} \mathrm{phases}$ become coarse, as shown in Fig. 1d.
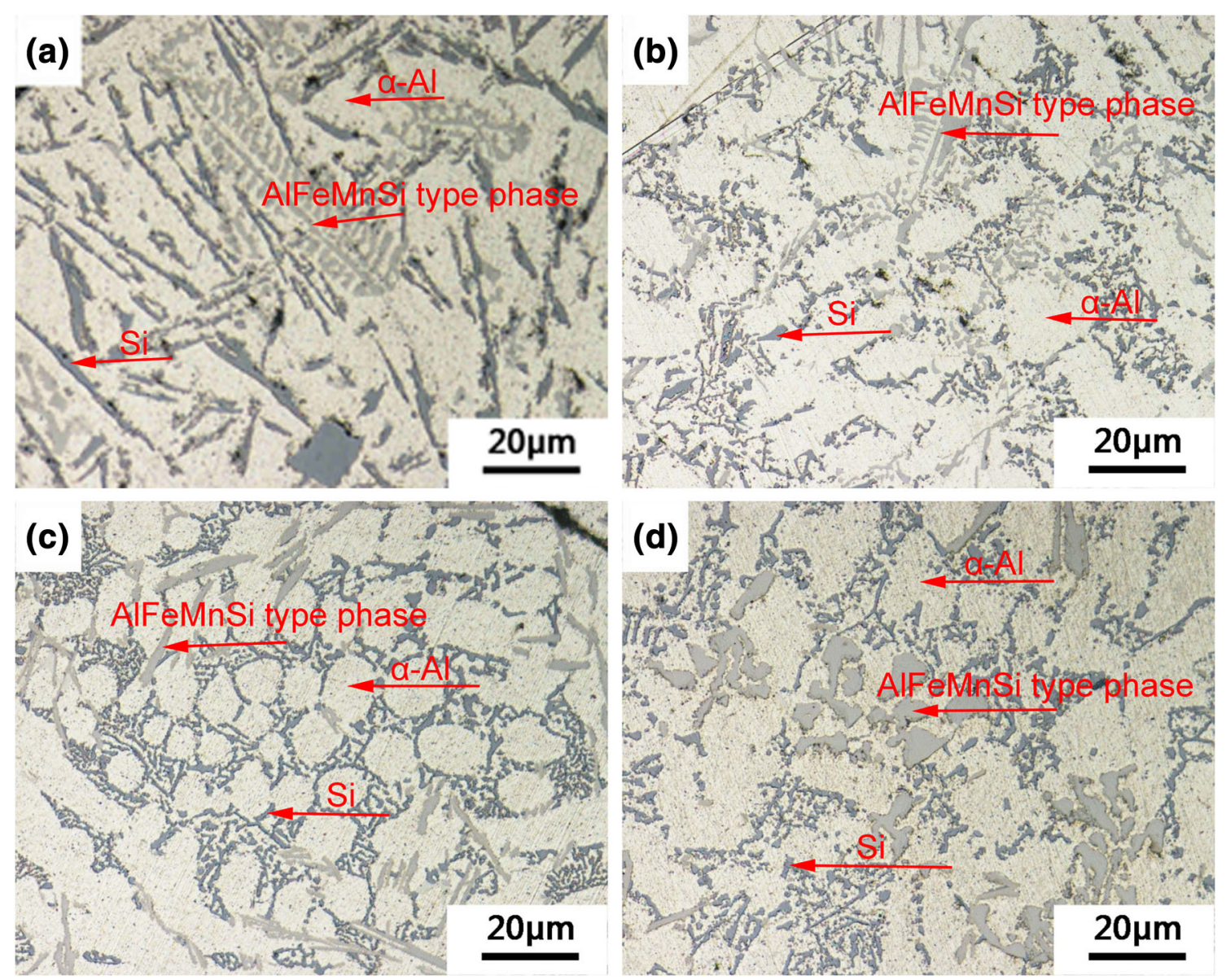

Fig. 1 Optical microstructures of uncorroded AlSi5Cu1Mg- $x \mathrm{La}$ alloy: a 0 wt $\% \mathrm{La} ; \mathbf{b} 0.3$ wt $\% \mathrm{La}$; 0.6 wt $\%$ La; d 0.9 wt $\% \mathrm{La}$
It can be concluded that La addition has a significant effect on the microstructure of $\mathrm{AlSi} 5 \mathrm{Cu} 1 \mathrm{Mg}$ alloy. With the increase in $\mathrm{La}$ content from 0 to $0.6 \mathrm{wt} \%$, the microstructure of $\mathrm{AlSi} 5 \mathrm{Cu} 1 \mathrm{Mg}$ alloys was continuously modified. However, the microstructure of $\mathrm{AlSi} 5 \mathrm{Cu} 1 \mathrm{Mg}-$ 0.9 La became coarse.

According to the theory of Mullins-Sekerka on interface-stability dynamics, the critical condition of keeping interface stable can be expressed as follows [18]:

$$
\begin{aligned}
G_{\mathrm{L}} / v \geq[ & \left.m_{\mathrm{L}} C_{0}(1-k) /\left(k D_{\mathrm{L}}\right)\right] \cdot\left[\left(k_{\mathrm{S}}+k_{\mathrm{L}}\right) /\left(2 k_{\mathrm{L}}\right)\right] \cdot \phi \\
& +\rho_{\mathrm{L}} H /\left(2 k_{\mathrm{L}}\right),
\end{aligned}
$$

where $k$ can be written as:

$k=C_{\mathrm{S}} / C_{\mathrm{L}}$,

where $G_{\mathrm{L}}$ represents the temperature gradient at the front of solid-fluid interface, $v$ represents the growth rate of solidfluid interface, $m_{\mathrm{L}}$ represents the slope liquidus line of alloy, $C_{0}$ represents the original composition of alloy, $k$ represents the solute partition coefficient, $D_{\mathrm{L}}$ represents the solute diffusion coefficient, $k_{\mathrm{S}}$ and $k_{\mathrm{L}}$ represent the thermal conductivities of solid phase and liquid phase, $\rho_{\mathrm{L}}$ 
represents the density of liquid phase, $H$ represents the latent heat of fusion, $\phi$ represents the non-dimensional parameter, and $C_{\mathrm{S}}$ and $C_{\mathrm{L}}$ represent the equilibrium solubility of solid phase and liquid phase.

When the La content was below $0.6 \mathrm{wt} \%$, La would be enriched at the front of solid-fluid interface during the solidification process due to its low solid solubility in the Al matrix. Therefore, it would block the diffusion of the solute and make the value of $C_{\mathrm{S}}$ decrease. Then, the critical value of $G_{\mathrm{L}} / v$ would increase, resulting in the increase in the composition undercooled interval. Furthermore, the composition undercooled value would exceed the condenser depression required by heterogeneous nucleation. Therefore, a new nucleation process would happen in the melt of this interval and cause the $\alpha$-Al to present a nearly spherical shape.

Researchers have reported that rare earth always assumes the atomic state and adsorbs on the growth eutectic silicon surface [19], which hindered the growth of the eutectic silicon phase and led to a change in the eutectic silicon morphology. In the process of AlSi5Cu1Mg alloy modified by $\mathrm{La}$, the growth of eutectic silicon was depressed by La elements. La is a surface-active element and exists in two types of adsorbed styles. On the one hand, La was adsorbed on the growth surface of Si $\{111\}$; on the other hand, the La was adsorbed on the interface of $\mathrm{Si}$ $\{100\}$ and $\mathrm{Al}\{110\}$. The former blocked the twin crystal growth kinetics and promoted eutectic Si refinement. The latter reduced the interplanar unworthy degree of $\mathrm{Si}\{100\}$ and $\mathrm{Al}\{110\}$ blocked the growth face of $\mathrm{Si}\{110\}$ and prompted the eutectic silicon particle growth. The mentioned two adsorbing styles made the eutectic $\mathrm{Si}$ growth in the direction of $\mathrm{Si}\{110\}$, and the growth face by $\mathrm{Si}\{111\}$, $\mathrm{Si}\{110\} / / \mathrm{Al}\{100\}$ was coherent interface strip structure of the branches. Therefore, La addition was changed the liquid-solid interface growth way of the eutectic silicon phase, which changed the morphology of eutectic silicon (as shown in Fig. 1a, c).

\subsection{SEM Analysis of AISi5Cu1Mg Alloy with La Addition}

The backscattered SEM images of AlSi5Cu1Mg-0.9La alloy with area scanning analysis are displayed in Fig. 2. Many bright white needle-like phases were found in the backscattered electron image of the AlSi5Cu1Mg-0.9La alloy. The generation of backscattered electrons increased monotonically with the number of the sample atomic. Therefore, the backscattered electron images can reflect the difference in the composition of the various parts (different phases) of the sample. The atomic number difference between $\mathrm{Si}$ and $\mathrm{Al}$ was small, and they showed dark gray in backscattered electron images. However, the atomic number of La was much larger than the one of $\mathrm{Si}$ or Al. The bright white needle-like phases could be La-rich intermetallic compounds in the AlSi5Cu1Mg alloy. To further investigate the main components of bright white needlelike phases, an area scanning of bright white needle-like phases is shown in Fig. 2. The main components of the bright white needle-like phases center region were $\mathrm{Al}, \mathrm{Cu}$ and La elements. As a result, the bright white needle-like phases could be $\mathrm{La}-\mathrm{Al}-\mathrm{Cu}$ intermetallic compounds.

The mixing enthalpy of $\Delta H_{\{A-\mathrm{La}\}}(A$ is $\mathrm{Si}, \mathrm{Al}, \mathrm{Cu}$ and $\mathrm{Fe})$ calculated by Miedema's model was $-73,-38$, $-21,5 \mathrm{~kJ} / \mathrm{mol}$, respectively [20]. The mixing enthalpy values showed strong affinity between $\mathrm{La}$ and $\mathrm{Si}$. However, some scholars have suggested that $\mathrm{La}$ and $\mathrm{Si}$ are unable to form chemical compounds and La was just attached to the surface of Si phases and changed their morphology [21]. Therefore, the $\mathrm{La}-\mathrm{Al}-\mathrm{Cu}$ phase formed more easily than the other phases. Figure 3 shows a backscattered SEM image and the corresponding EDS analysis of the AlSi5$\mathrm{Cu} 1 \mathrm{Mg}-0.9 \mathrm{La}$ alloy, which was extracted by $20 \mathrm{wt} \%$ $\mathrm{NaOH}$ solution for $20 \mathrm{~min}$. The bright white needle-like phase was the $\mathrm{La}-\mathrm{Al}-\mathrm{Cu}$ phase, and the gray was $\mathrm{Si}$. The $\mathrm{La}-\mathrm{Al}-\mathrm{Cu}$ phase was firmly attached to the surface of $\mathrm{Si}$.

\subsection{Corrosion Behavior of AISi5Cu1Mg Alloy with Different Contents of La}

The typical linear scan voltammetry curves of AlSi5$\mathrm{Cu} 1 \mathrm{Mg}$ samples with different contents of $\mathrm{La}$ are presented in Fig. 4 a. The corrosion potential $\left(E_{\text {corr }}\right)$ and corrosion current density $\left(I_{\text {corr }}\right)$ were estimated via linear scan voltammetry tests, and the results are plotted in Fig. 4b. The linear scan voltammetry curves show that the polarization curve slopes of the anode and cathode increased with the increase in La contents. Furthermore, the polarization curve slopes of cathode curves were larger than those of the anode curves. The greater the polarization curve slope, the greater the electrode reaction resistance. In Fig. $4 \mathrm{a}$, the corrosion potential of each $\mathrm{AlSi} 5 \mathrm{Cu} 1 \mathrm{Mg}-x \mathrm{La}$ alloy was higher than that of matrix alloy, and the corresponding corrosion current density was lower. When adding $0.6 \mathrm{wt} \%$ of $\mathrm{La}$, the corrosion potential suffered an increase in the positive direction compared to the matrix alloy, which indicated strong cathodic inhibition (the corrosion potential from -627 up to $-591 \mathrm{mV}$ vs. SCE) and the corrosion current density of the modified alloy changed from 58 to $22 \mu \mathrm{A} / \mathrm{cm}^{2}$. According to Faraday's law, the corrosion rate is proportional to the corrosion current density [22]. Furthermore, the corrosion current density of the AlSi5Cu1Mg-0.6La alloy was about $40 \%$ of the matrix alloy; thus, the corrosion rate of the AlSi $5 \mathrm{Cu} 1 \mathrm{Mg}-0.6 \mathrm{La}$ alloy was the slowest and the corrosion resistance was best. It can be concluded that the corrosion resistance of 
(a)

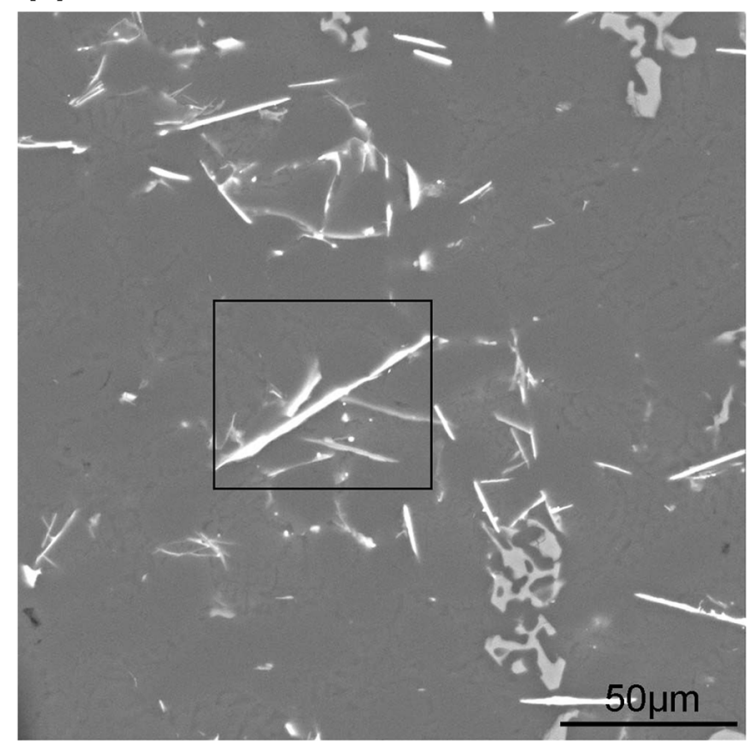

(c)

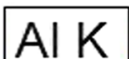

(b)

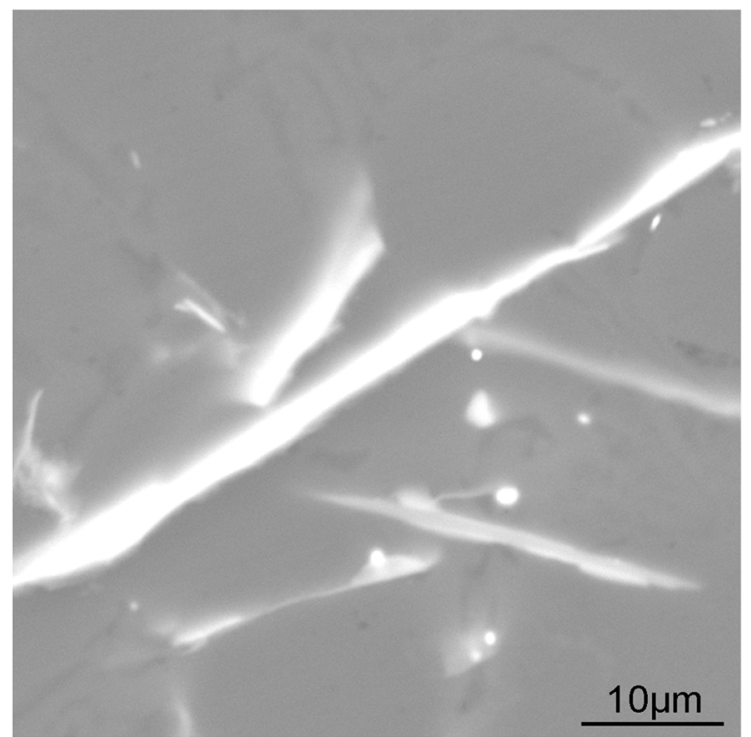

(d)

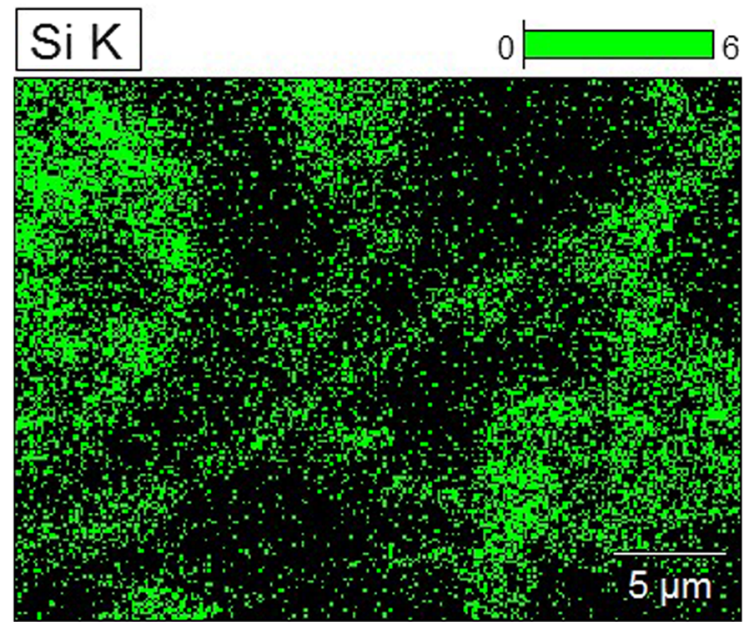

(f)

(e)

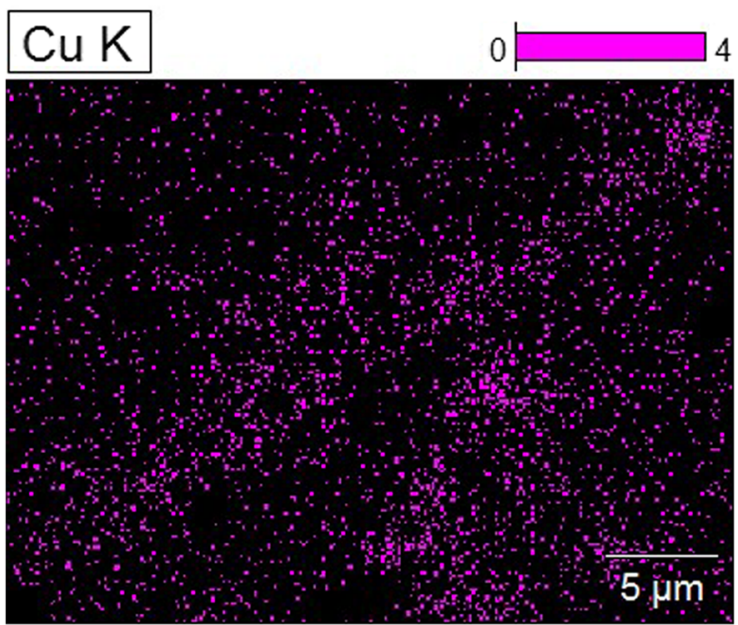

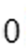

o) 6

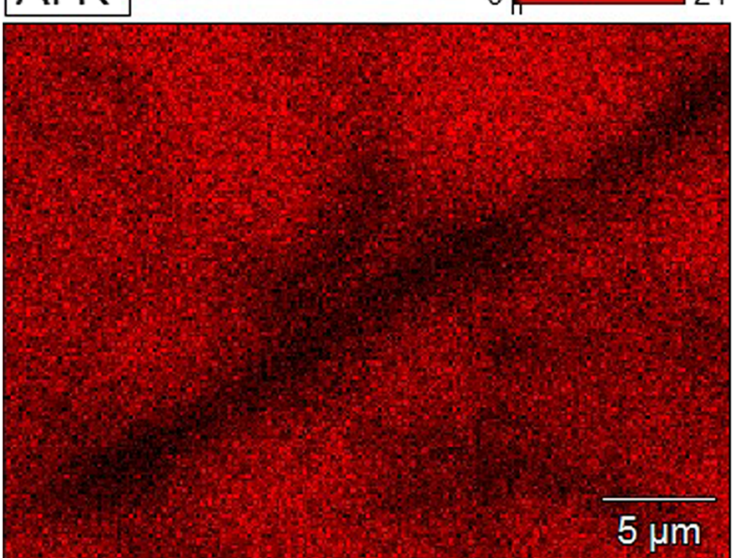

La L

6

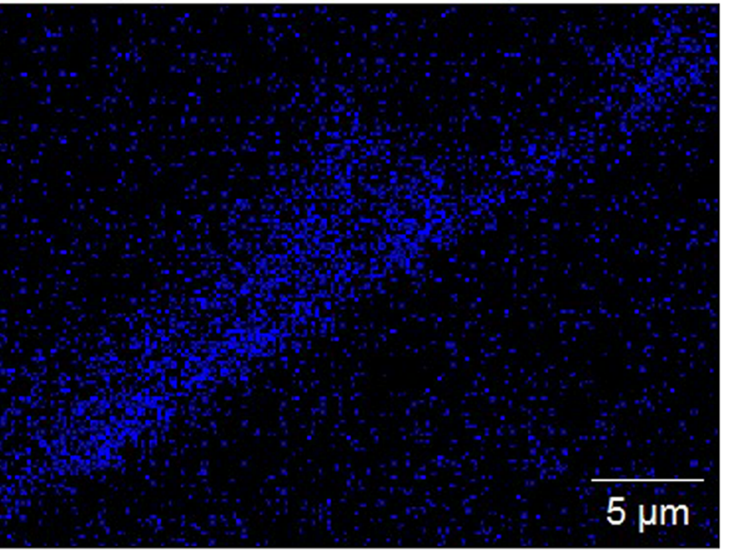

Fig. 2 Backscattered SEM images of AlSi5Cu1Mg-0.9La at low a, high $\mathbf{b}$ magnification and area scanning of La-rich intermetallic compounds of elements $\mathrm{Al} \mathbf{c}, \mathrm{Si} \mathbf{d}, \mathrm{Cu}$ e, $\mathrm{La} \mathbf{f}$ 
(a)
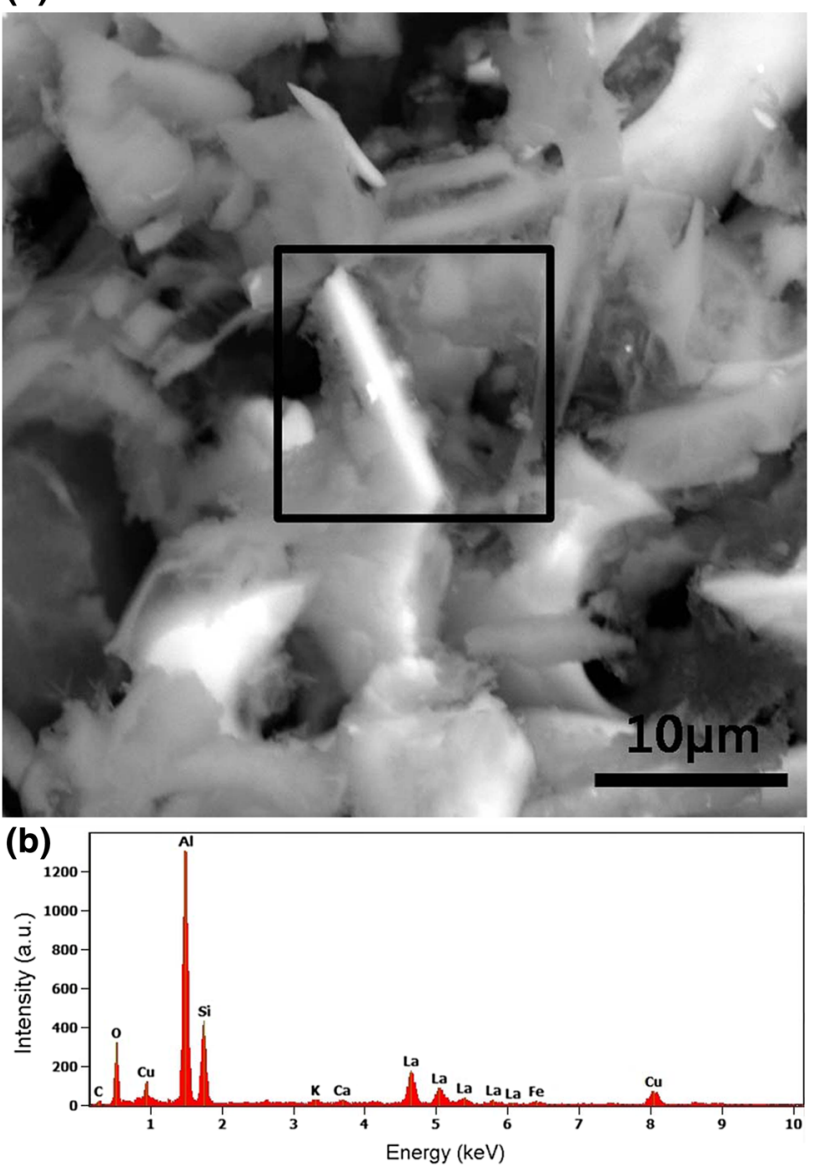

Fig. 3 Backscattered SEM image a, EDS analysis b of AlSi5Cu1Mg$0.9 \mathrm{La}$ alloy extracted by $20 \mathrm{wt} \% \mathrm{NaOH}$ solution with $20 \mathrm{~min}$
AlSi5Cu1Mg alloy can be improved by a suitable content of $\mathrm{La}$ additive

The surface morphologies of AlSi5Cu1Mg- $x$ La alloy immersed in $3.5 \mathrm{wt} \% \mathrm{NaCl}$ solution for 60 days are shown in Fig. 5. Figure 5a shows that the surface of the matrix alloy has a large corrosion pit, many peeling layers and white corrosion products. As shown in Fig. 5b, compared to the matrix alloy, the AlSi5Cu1Mg-0.3La has a more alleviative surface corrosion morphology, smaller size of the peeling layer, and fewer corrosion products. When the content of La increased to $0.6 \mathrm{wt} \%$, the corrosion area of the AlSi5Cu1Mg-0.6La alloy surface decreased noticeably, as shown in Fig. 5c. Here, no corrosion pit was found, and the corrosion products were few. However, further increasing the La content to $0.9 \mathrm{wt} \%$ intensified the surface exfoliation and the corrosion resistance of $\mathrm{AlSi} 5 \mathrm{Cu} 1 \mathrm{Mg}$ 0.9La alloy deteriorated, as shown in Fig. 5d.

From the viewpoint of electrochemical theory, the corrosion potentials of various phases in $\mathrm{Al}-\mathrm{Si}-\mathrm{Cu}$ alloy differ, and the corrosion behavior always initiates at the $\alpha$-Al matrix in the adjacent areas of the eutectic Si, AlFeMnSitype phase and $\mathrm{Cu}$-rich phase [23]. The above results show that La significantly affects the corrosion resistance of the AlSi5CuMg alloy. The La content in the alloy was below $0.6 \mathrm{wt} \%$. The surface of the eutectic Si was coated with La, which led to the refinement of eutectic Si. Compared to other samples, the AlSi5Cu1Mg-0.6La sample exhibited fewer susceptible grain boundaries due to its excellent microstructures. As a result, the AlSi5Cu1Mg-0.6 $\mathrm{La}$ sample had fewer interdendritic imperfections [24] and corrosion regions than other samples.

(b)

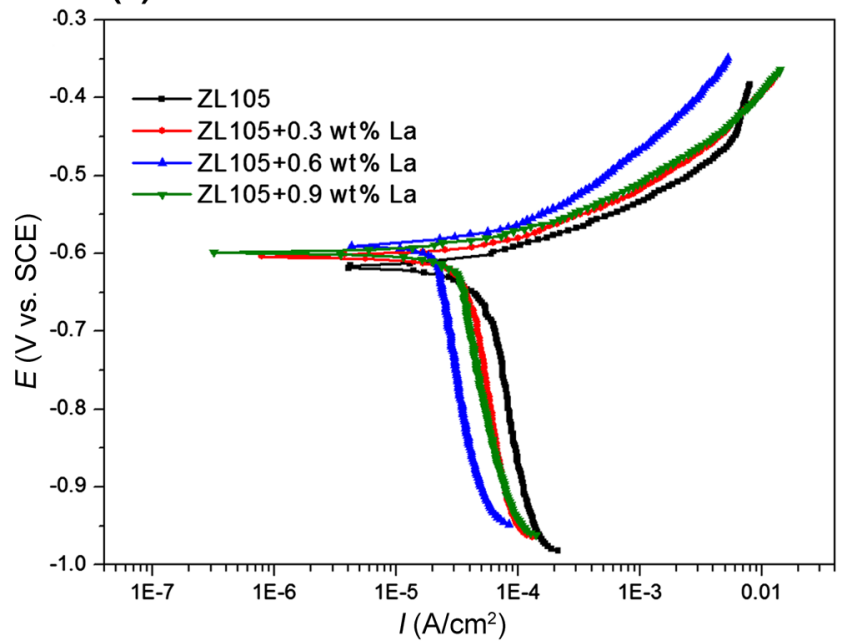

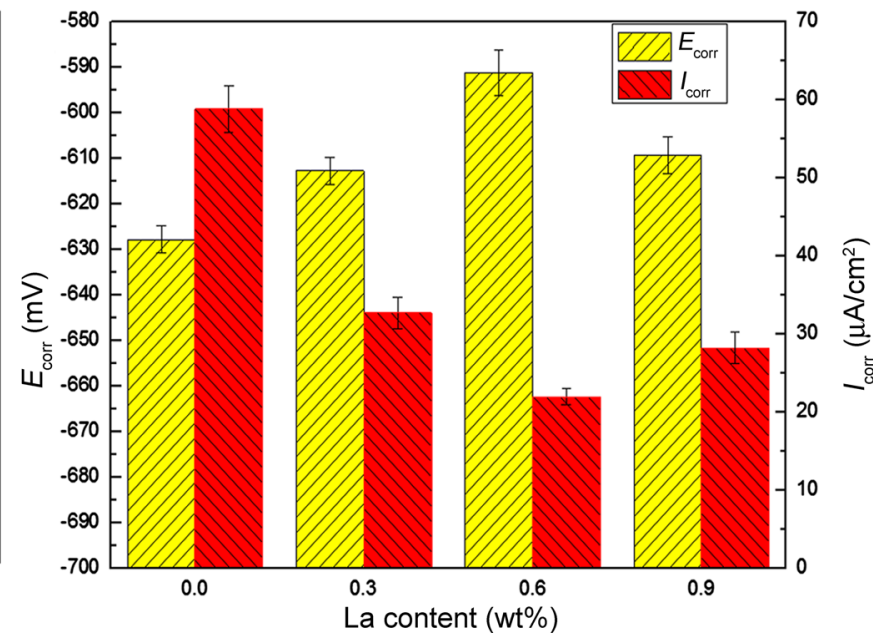

Fig. 4 a Linear scan voltammetry curves of $\mathrm{AlSi} 5 \mathrm{Cu} 1 \mathrm{Mg}-x \mathrm{La}$ alloy in $3.5 \mathrm{wt} \% \mathrm{NaCl}$ solution, $\mathbf{b}$ corrosion potential $\left(E_{\text {corr }}\right)$ and corrosion current density $\left(I_{\text {corr }}\right)$ calculated from linear scan voltammetry curves ( $E$ : potential; $I$ : current density) 

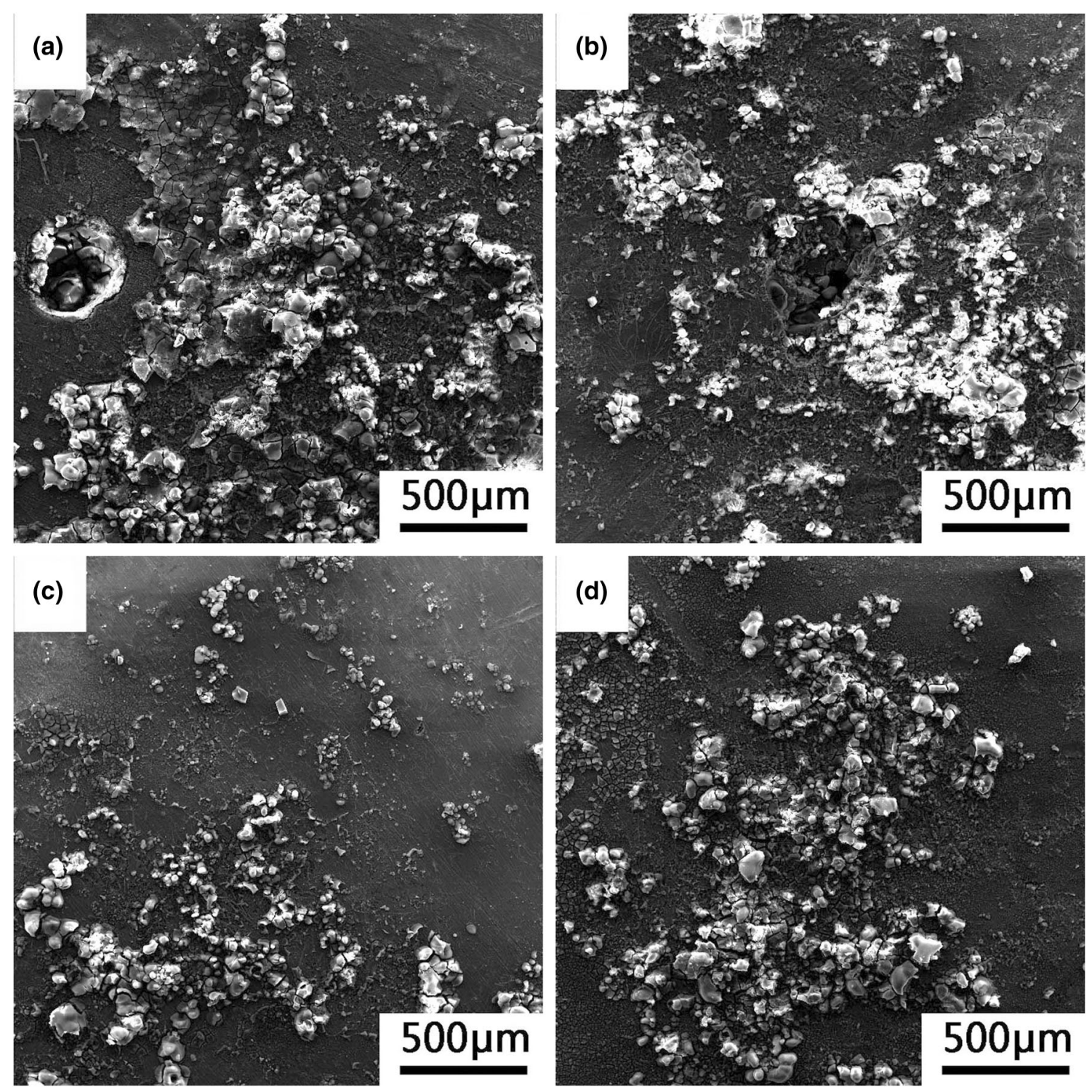

Fig. 5 SEM images of corrosion morphologies of AlSi5Cu1Mg- $x \mathrm{La}$ alloy: a AlSi5Cu1Mg; b AlSi5Cu1Mg-0.3La; c AlSi5Cu1Mg-0.6La; d $\mathrm{AlSi} 5 \mathrm{Cu} 1 \mathrm{Mg}-0.9 \mathrm{La}$

$\mathrm{La}$ and $\mathrm{Cu}$ have a good affinity $(\Delta H=-21 \mathrm{~kJ} / \mathrm{mol})$; therefore, $\mathrm{La}$ would be attached to the surface of $\mathrm{Cu}$-rich phases and a covering film formed, which hindered the corrosion electron flowing between the cathode and the anode, and the corrosion resistance of alloy was improved. However, the microstructure of the AlSi5Cu1Mg alloy was refined by a suitable content of $\mathrm{La}$. Then, the surface area of the exposed anode $\alpha$-Al was bigger than the cathode areas of $\mathrm{Si}$, Cu-rich phases and AlFeMnSi-type phases; therefore, it could be indicated that the corrosion resistance of the resulting alloy was improved. In addition, according to one-dimensional galvanic theory [25], the Faradic anodic corrosion current density $\left(I_{\mathrm{F}}^{\mathrm{g}}\right)$ at the anode/cathode interface can be expressed as:
$I_{\mathrm{F}}^{\mathrm{g}}=\frac{\left(E_{\mathrm{corr}}^{\mathrm{c}}-E_{\mathrm{corr}}^{\mathrm{a}}\right)}{{ }_{c}^{a} \rho_{\mathrm{p}}^{\mathrm{c}}+\rho_{\mathrm{p}}^{\mathrm{a}}+\rho_{\mathrm{s}}}$,

where $a$ and $c$ represent the lengths (sizes of areas) of the anode and cathode; $E_{\mathrm{corr}}^{\mathrm{c}}$ and $E_{\mathrm{corr}}^{\mathrm{a}}$ represent the open circuit potentials of cathode and anode; $\rho_{\mathrm{p}}^{\mathrm{c}}$ and $\rho_{\mathrm{p}}^{\mathrm{a}}$ represent the cathodic and anodic polarization resistivities; and $\rho_{\mathrm{s}}$ represents the solution resistivity. The values of $E_{\text {corr }}$ and $I_{\text {corr }}$ vary with the microstructures shown in Fig. 4b, which may be caused by the addition of La element. According to Eq. (3), the addition of La changed the local potential and the size of anode and cathode $(a / c)$, which caused the corrosion current difference in $\mathrm{AlSi} 5 \mathrm{Cu} 1 \mathrm{Mg}-x \mathrm{La}$ alloy. It can be concluded that good corrosion resistance properties are dependent on the morphology and volume fraction of 

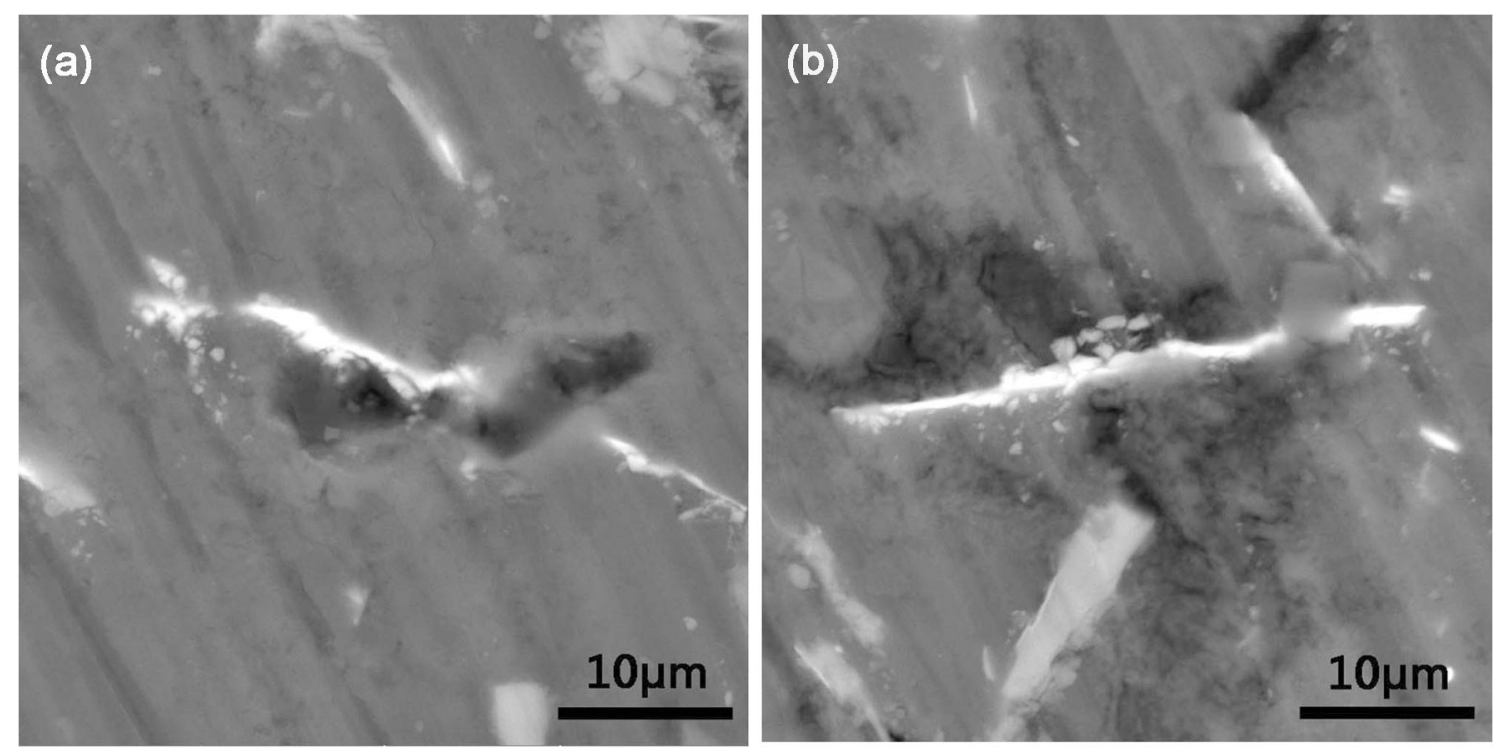

Fig. 6 Morphologies of micro-galvanic corrosion reaction between $\mathrm{La}-\mathrm{Al}-\mathrm{Cu}$ phase and surrounding $\alpha$-Al after immersion for 30 days a, 60 days b

the main phase components $(\alpha-\mathrm{Al}$ and $\mathrm{Si})$ and intermetallic compound.

When the contents of La increased to $0.9 \mathrm{wt} \%$ and exceeded the amount of its solubility in the AlSi5Cu1Mg alloy, numerous bright white needle-like $\mathrm{La}-\mathrm{Al}-\mathrm{Cu}$ phases were formed in the alloy. Figure 6 shows that in the immersion test, those $\mathrm{La}-\mathrm{Al}-\mathrm{Cu}$ phases in the AlSi5$\mathrm{Cu} 1 \mathrm{Mg}-0.9 \mathrm{La}$ alloy acted as cathodic phase like the effect of $\mathrm{Cu}$-rich and AlFeMnSi-type phases in the AlSi5Cu1Mg alloy. Furthermore, a micro-galvanic corrosion reaction occurred between the $\mathrm{La}-\mathrm{Al}-\mathrm{Cu}$ phase and the surrounding $\alpha$-Al. As a result, the corrosion resistance of the AlSi5$\mathrm{Cu} 1 \mathrm{Mg}-0.9 \mathrm{La}$ alloy is deteriorated.

\section{Conclusions}

AlSi5Cu1Mg alloy samples were modified by different contents $(0,0.3,0.6$ and $0.9 \mathrm{wt} \%)$ of La. Electrochemical measurement and immersion tests of the samples were conducted. The effects of $\mathrm{La}$ on the microstructures and corrosion behaviors of AlSi5Cu1Mg alloy were investigated:

1. The resulting microstructures of $\mathrm{AlSi} 5 \mathrm{Cu} 1 \mathrm{Mg}$ alloy depended on the distribution and the content of the La additive. The AlSi5Cu1Mg-0.6La alloy achieved the best cellular microstructures, and its corrosion resistance was the best among the investigated samples. The AlSi5Cu1Mg-0.6La alloy was characterized by the highest values of $E_{\text {corr }}(-591 \mathrm{mV}$ vs. SCE) and the lowest values of $I_{\text {corr }}\left(22 \mu \mathrm{A} / \mathrm{cm}^{2}\right)$. Furthermore, the corrosion current density of the AlSi5Cu1Mg-0.6La alloy was about $40 \%$ of that of the AlSi5Cu1Mg alloy.

2. The corrosion resistance of the AlSi5Cu1Mg alloy was affected by the microstructures. When the La content did not exceed $0.6 \mathrm{wt} \%$, the surfaces of the eutectic Si and $\mathrm{Cu}$-rich phases were coated with $\mathrm{La}$. The covering film of $\mathrm{La}$ hindered the corrosion electron flow between cathode and anode. Therefore, the corrosion resistance of AlSi5Cu1Mg-0.3La alloy and AlSi5$\mathrm{Cu} 1 \mathrm{Mg}-0.6 \mathrm{La}$ alloy was improved, compared to the matrix alloy. However, as the contents of La increased to $0.9 \mathrm{wt} \%$, the micro-galvanic corrosion reaction occurred between the $\mathrm{La}-\mathrm{Al}-\mathrm{Cu}$ phase and the surrounding $\alpha-\mathrm{Al}$. As a result, the corrosion resistance of the AlSi5Cu1Mg-0.9La alloy is deteriorated.

Acknowledgements This research is supported financially by the National Natural Science Foundation of China (No. 51364035) and the Natural Science Foundation of Jiangxi Province (No. 20171BAB206034).

\section{References}

[1] X.H. Chen, H. Yan, J. Alloys Compd. 708, 129 (2014)

[2] J.B. Zhu, H. Yan, H.Y. Ye, F.R. Ai, J. Centr, South Univ. 24, 1934 (2017)

[3] H. Yan, F.H. Chen, Z.H. Li, J. Rare Earth 34, 938 (2016)

[4] Q.J. Wu, H. Yan, P.X. Zhang, X.Q. Zhu, Q. Nie, Acta Metall. Sin (Engl. Lett.) 31, 523 (2018)

[5] J.J. Pang, F.C. Liu, J. Liu, M.J. Tan, D.J. Blackwood, Corros. Sci. 106, 217 (2016) 
[6] A. Raul, M. Beatriz, A. Pardo, M. Marta, M. Endzhe, R.D. Ivan, Corros. Sci. 73, 342 (2013)

[7] T. Fatih, A. Alexandra, I. Kerti, A. Edith, A.R. Luis, Wear 306, 27 (2013)

[8] A.C. Vieira, M.P. Ana, A.R. Luis, M. Stefano, Electrochim. Acta 56, 3821 (2011)

[9] L. Milosev, B. Volaric, Corrosion 73, 822 (2017)

[10] B.S. Gu, L. Gong, P.Y. Yang, Rare Met. Mater. Eng. 43, 429 (2014)

[11] C.L. Wang, Y. Gao, Rare Met. Mater. Eng. 46, 812 (2017)

[12] K.L. Wang, Q.B. Zhang, M.L. Sun, X.G. Wei, Y.M. Zhu, Corros. Sci. 43, 255 (2001)

[13] X. Zhang, Z.H. Wang, Z.H. Zhou, J.M. Xu, J. Alloys Compd. 698, 241 (2016)

[14] Y. Wang, R.K. Gupta, N.L. Sukiman, R. Zhuang, C.H.J. Davies, N. Birbilis, Corros. Sci. 73, 181 (2013)

[15] A.M. Cardinalea, D. Macciò, G. Luciano, E. Canepa, P. Traverso, J. Alloys Compd. 695, 2180 (2016)
[16] F. Mao, G.Y. Yan, Z.J. Xuan, Z.Q. Cao, T.M. Wang, J. Alloys Compd. 650, 896 (2015)

[17] Z.H. Li, H. Yan, Z. Hu, X.C. Song, Rare Met. 9, 1 (2014)

[18] X. Huang, H. Yan, J. Wuhan Univ. Technol. 28, 202 (2013)

[19] S.C. Wang, N. Zhou, D.F. Song, D. Nong, Mater. Sci. Forum 898, 367 (2017)

[20] A. Takeuchi, A. Inoue, Metall. Mater. Trans. A 46, 2817 (2005)

[21] L.J. Jing, Y. Pan, T. Lu, C.L. Li, J.H. Pi, N.Y. Sheng, J. Mater. Eng. Perform. 27, 1 (2018)

[22] Y. Zou, J. Wang, Y.Y. Zheng, Corros. Sci. 53, 208 (2011)

[23] A. Raul, M. Beatriz, A. Pardo, M. Marta, M. Endzhe, C.M. Maria, A. Rivas, Mater. Corros. 66, 535 (2015)

[24] G. Srinivas, P.C. Jesus, V.V. Edna, M. Casales, D.M. Ortega, M.G. Lorenzo, J. Spectrosc. 2015, 1 (2015)

[25] H.M. Jia, X.H. Feng, Y.S. Yang, Corros. Sci. 120, 75 (2017) 